\title{
Evaluation of Techniques for the Diagnosis of Strongyloides stercoralis in Human Immunodeficiency Virus (HIV) Positive and HIV Negative Individuals in the City of Itajaí, Brazil
}

\begin{abstract}
Human immunodeficiency virus (HIV) and intestinal parasites are common in Brazil. Previous studies have shown that infection with Strongyloides stercoralis is frequently associated with HIV infection. Strongyloidiasis is difficult to diagnosis and stool examination with conventional techniques fails to detect the helminth larvae. We made a prospective study, to test the efficacy of the agar plate technique to detect $S$. stercoralis in $211 \mathrm{HIV}$-positive patients and $213 \mathrm{HIV}$-negative patients in the city of Itajaí, Brazil, between September 2001 and June 2002. The feces samples of these patients were processed and analyzed according to the following methods: Lutz, formalin ethyl acetate, Baermann, Harada-Mori and agar plate culture. HIV-positive patients were more frequently infected by $\boldsymbol{S}$. stercoralis (odds ratio= 5,.687). Among the methods used on fecal specimens, the larvae of $S$. stercoralis were most efficiently detected by the agar plate $(69.7 \%)$ method, followed by the Baermann and the formalin ethyl acetate methods $(48.5 \%)(P=0.01)$, Lutz $(42.4 \%)(P=0.01)$, and Harada-Mori culture $(24 \%)(P=0.001)$. Therefore agar plate culture is the most efficient method for the detection of $S$. stercoralis larvae and this technique should be the test of choice, especially in immunocompromised patients.

Key Words: Agar plate culture, HIV, Strongyloides stercoralis.
\end{abstract}

The intestinal nematode $S$. stercoralis is widely distributed throughout the tropical and sub-tropical regions of the world, affecting 30 million people in 70 countries [1]. Brazil and Thailand are, however, the countries with the highest known prevalence of this parasite [2].

Infection by $S$. stercoralis is usually asymptomatic or only clinically abnormal. However, a debilitated immunological system may result in a more serious manifestation of this disease, with a possible increase of autoinfection mechanisms [3-5]. It has been postulated that helminths, such as S. stercoralis, produce different types of intestinal infection in HIV-

Received on 08 May 2003; revised 04 August 2003.

Address for correspondence: Dr..Geny Aparecida Cantos. Departamento de Análises Clínicas da Universidade Federal de Santa Catarina (UFSC), 476 Florianópolis, Brazil, Zip code: 88040-900. E-mail address:geny@ ccs.ufsc.br

The Brazilian Journal of Infectious Diseases 2003;7(6):402-408 (C) 2003 by The Brazilian Journal of Infectious Diseases and Contexto Publishing. All rights reserved. infected patients, such as chronic diarrhea [6]. This may be due to fact that HIV-induced enteropathy does not favor the establishment of intercellular parasites [7]. Studies made on HIV-positive patients have shown that the morbidity caused by $S$. stercoralis can be quite debilitating [8,9], and therefore correct diagnosis of this parasite is of great importance.

Due to the ease of preparation, low cost and timesaving benefits, parasitological methods based on a search for larvae in the feces are still a common choice among laboratory procedures for the diagnosis of this helminth. The most traditionally employed methods are Rugai's and Baermann's [9]. Recently, the agar plate culture method has been tested and comparisons have been made with direct smears, formalin ethyl acetate and Harada Mori culture methods [10-12]. However, there has not been much comparison of this method with Baermann's [13]. We compared the agar plate culture method, for the diagnosis of $S$. stercoralis, with other parasitological methods, especially with Baermann's, in patients infected or not with HIV. 


\section{Materials and Methods}

Study population. We examined the stools of 424 patients, both men and women, more than 18 years old, 211 of which were HIV-positive (diagnosis made with the anti-HIV 1 and 2 antibodies test and confirmed by indirect immunofluorescence and Western-Blot), attended at Hospital Dia at the Univale Laboratório Escola, Itajaí, Brazil. The other 213 were HIVnegative.

This project was approved by the Ethics Committee of the Universidade Federal de Santa Catarina (UFSC) and UNIVALI (Itajaî), and all patients signed informed consent forms.

Each patient provided one stool specimen, without preservative, for the fecal analysis and the following analyses were performed: Lutz, formalin ethyl acetate, Harada-Mori culture [14], and agar plate culture, according to a previously described method $[9,10]$.

In the agar plate test, about $3 \mathrm{~g}$ to $4 \mathrm{~g}$ of feces were placed on the center of a primary agar-plate in a $100 \mathrm{x}$ $15 \mathrm{~mm}$ Petri dish. The Petri dish was sealed with adhesive tape and stored at room temperature for two days. After this period, the surface of the agar-plate was analyzed daily with an inverted microscope for the presence of tracks, moving larvae or free-living adults. Independently of what was observed after this period, $5 \mathrm{ml}$ of a $10 \%$ formalin solution were added to the agar surface and, after 5 minutes, the excess formalin was placed in a centrifuge tube and centrifuged at 1,500; Lugol was then added to the material and the final extract was analyzed in a microscope.

Statistical analysis. The parasite frequency on HIVpositive and HIV-negative patients was compared by Chi square analysis and by Fisher's exact test. The comparison with the efficiency of the plate agar method for the identification of S. stercoralis was made with a simple proportions test, and the odds ratio was calculated based on the comparative analysis of the occurrence of strongyloidiasis in HIVpositive and HIV-negative patients. The accepted significance level was $5 \%$.

\section{Results}

A total of 424 patients, among which 211 were positive and 213 were negative for HIV, were included in this study. Most of the patients were from 18-40 years of age ( $70.1 \%$ from the HIV-positive group and $67.6 \%$ from the HIV-negative group). In the HIVpositive group, $59.2 \%$ were male patients, whereas $63.8 \%$ were female patients in the HIV-negative group. The combined results of stool examinations are shown in Table 1. Thirty five of the HIV-positive patients (16.6\%) and 46 HIV-negative patients (21.6\%) were infected by at least one intestinal parasite. Strongyloides stercoralis, Ascaris lumbricoides, Trichiuris trichiura, Endolimax nana, Giardia lamblia and Entamoeba coli were detected in both groups of patients. Ten percent (21/35) of the HIV-positive patients were infected by $S$. stercoralis, $2.4 \%(5 / 35)$ by $A$. lumbricoides, $1.8 \%(4 / 35)$ by $E$. nana, and $0.5 \%$ (1/35) were infected by G. lamblia. Significant differences in the rate of infection by intestinal parasites between the HIV-positive and HIV-negative patients was found only for E. nana $(\mathrm{P}<0.001)$ and $E$. coli $(\mathrm{P}<0.05)$.

There was a predominance of infection by $S$. stercoralis when compared to other parasites in HIVpositive patients (Table 2). This group of patients appeared to be five times more susceptible to infection by this helminth, compared to the HIV-negative group. Table 3 shows the results obtained in the diagnosis of intestinal parasites using five methods. The formalinethyl acetate method was superior for the detection of protozoan cysts and certain helminth eggs, while Lutz's method was efficient for the detection of $A$. lumbricoides only. S. stercoralis was found in 33 of the 424 samples. Among the 33 Strongyloides-positive samples, $23(69.7 \%)$ were identified using the agar plate method, $16(48.5 \%)$ using the Baermann and formalin ethyl acetate method, 14 (42.4\%) using Lutz's method and only 8 (24\%) were identified using the HaradaMori culture technique. A direct analysis showed that the plate culture method was significantly more efficient for the detection of S. stercoralis larvae than Lutz's method $(\mathrm{P}<0.012)$, formalin ethyl acetate and 
Table 1. The distribution rate (percentage) of parasite infections in immunodeficiency virus (HIV) positive and HIV negative individuals in Itajaí, SC, Brazil

\begin{tabular}{|c|c|c|c|c|c|c|c|}
\hline \multirow[t]{2}{*}{ Parasites } & \multicolumn{2}{|c|}{$\begin{array}{l}\text { HIV positive patients } \\
\qquad(\mathrm{n}=211)\end{array}$} & \multicolumn{2}{|c|}{$\begin{array}{l}\text { HIV negative patients } \\
\qquad(\mathrm{n}=\mathbf{2 1 3})\end{array}$} & \multicolumn{2}{|c|}{ Total } & \multirow{2}{*}{$\begin{array}{c}\text { Values } \\
\text { p }\end{array}$} \\
\hline & $\mathbf{N}^{\circ}$ & $\%$ & $\mathbf{N}^{\circ}$ & $\%$ & $\mathbf{N}^{\circ}$ & $\%$ & \\
\hline \multicolumn{8}{|l|}{ Helminths } \\
\hline S. stercoralis & 21 & 10.0 & 12 & 5.6 & 33 & 7.8 & $0.097^{\mathrm{a}}$ \\
\hline A. lumbricoides & 5 & 2.4 & 11 & 5.2 & 16 & 3.8 & $0.131^{\mathrm{a}}$ \\
\hline T. trichiura & 1 & 0.5 & 3 & 1.4 & 4 & 0.9 & $0.623^{\mathrm{b}}$ \\
\hline Hookworm & 0 & 0 & 3 & 1.4 & 3 & 0.7 & $0.248^{b}$ \\
\hline Trichostrongylus & 0 & 0 & 2 & 0.9 & 2 & 0.9 & $0.498^{b}$ \\
\hline Taenia spp. & 1 & 0.5 & 0 & 0 & 1 & 0.2 & $0.498^{b}$ \\
\hline \multicolumn{8}{|l|}{ Protozoans } \\
\hline Endolimax nana & 4 & 1.8 & 19 & 8.9 & 23 & 5.4 & $0.001^{\mathrm{b} * *}$ \\
\hline Giardia lamblia & 1 & 0.5 & 4 & 1.9 & 5 & 1.2 & $0.372^{\mathrm{b}}$ \\
\hline Entamoeba coli & 2 & 0.9 & 10 & 4.7 & 12 & 2.8 & $0.036^{\mathrm{b}^{*}}$ \\
\hline Isospora belli & 2 & 0.9 & 0 & 0 & 2 & 0.5 & $0.247^{b}$ \\
\hline
\end{tabular}

$\mathrm{a}=$ Chi-square statistic; $\mathrm{b}=$ Fisher's exact test; $\mathrm{n}^{\mathrm{o}}=$ number of patients. $(* \mathrm{P}<0.05 ; * * \mathrm{P}<0.001)$.

Table 2. Frequency of occurrence of Strongyloides stercoralis larvae in HIV-positive and HIV-negative patients in Itajaí, SC, Brazil

\begin{tabular}{|c|c|c|c|c|c|c|}
\hline \multirow[t]{2}{*}{ Strongyloides stercoralis } & \multicolumn{2}{|c|}{ HIV-positive patients } & \multicolumn{2}{|c|}{ HIV-negative patients } & \multirow[t]{2}{*}{ OR } & \multirow[t]{2}{*}{$95 \% \mathrm{CI}$} \\
\hline & No. & $(\%)$ & No. & $(\%)$ & & \\
\hline Positive & 21 & $(63.6)$ & 12 & (36.4) & 5.687 & $\begin{array}{l}2,303 \\
14,043\end{array}$ \\
\hline Negative & 16 & $(23.5)$ & 52 & (76.5) & 1 & \\
\hline
\end{tabular}

OR: odds ratio; $\mathrm{CI}$ : interval confidence.

Baermann's methods $(\mathrm{P}<0.03)$ and the Harada-Mori culture Technique $(\mathrm{P}<0.001$, Table 4$)$.

\section{Discussion}

The city of Itajaí has the most HIV cases in the state of Santa Catarina, Brazil. Approximately 78 new cases of infection are reported per year per 100,000 inhabitants [15]. The occurrence of strongyloidiasis in the state of Santa Catarina is relatively high, although only a few epidemiological studies on this region have been made [16].

We investigated differences in the rate of infection by enteric parasites, especially S. stercoralis, in HIVpositive and HIV negative individuals in this city. Strongyloides stercoralis was the most frequently 
Table 3. Comparison of parasitological methods for the diagnosis of intestinal parasites in Itajaí, SC, Brazil $(n=424)$

\begin{tabular}{|c|c|c|c|c|c|c|c|c|c|c|c|}
\hline \multirow[t]{2}{*}{ Parasites* } & \multicolumn{2}{|c|}{ Lutz } & \multicolumn{2}{|c|}{$\begin{array}{c}\text { Formalin- } \\
\text { ethyl acetate }\end{array}$} & \multicolumn{2}{|c|}{ Baermann } & \multicolumn{2}{|c|}{$\begin{array}{l}\text { Agar plate } \\
\text { culture }\end{array}$} & \multicolumn{2}{|c|}{$\begin{array}{c}\text { Harada- } \\
\text { Mori } \\
\text { culture }\end{array}$} & \multirow{2}{*}{$\begin{array}{c}\text { Total no. } \\
\text { parasite } \\
\text { infections } \\
(n=101)\end{array}$} \\
\hline & No. & $(\%)$ & No. & $(\%)$ & No. & $(\%)$ & No. & $(\%)$ & No. & $(\%)$ & \\
\hline \multicolumn{12}{|l|}{ Helminths } \\
\hline S. stercoralis & 14 & 42.4 & 16 & 48.5 & 16 & 48.5 & 23 & 69.7 & 8 & 24.0 & 33 \\
\hline A. lumbricoides & 15 & 93.8 & 12 & 75 & -- & -- & -- & -- & -- & -- & 16 \\
\hline Trichuris trichiura & 2 & 50 & 4 & 100 & -- & -- & -- & -- & -- & -- & 4 \\
\hline Hookworm & 1 & 33.3 & 2 & 66.7 & -- & -- & 1 & 33.3 & 2 & 66.7 & 3 \\
\hline Trichostrongylus spp. & 2 & 100 & -- & -- & -- & -- & -- & -- & -- & -- & 2 \\
\hline Taenia spp. & 1 & 100 & 1 & 100 & -- & -- & -- & -- & -- & -- & 1 \\
\hline \multicolumn{12}{|l|}{ Protozoans } \\
\hline Endolimax nana & 12 & 52.2 & 21 & 95.0 & -- & -- & -- & -- & -- & -- & 23 \\
\hline Giardia lamblia & 4 & 80 & 5 & 100 & -- & -- & -- & -- & -- & -- & 5 \\
\hline Entamoeba coli & 11 & 91.7 & 11 & 91.7 & -- & -- & -- & -- & -- & -- & 12 \\
\hline Isospora belli & 1 & 50 & 2 & 100 & -- & -- & -- & -- & -- & -- & 2 \\
\hline
\end{tabular}

* (--) indicates that a particular method was not tested.

Table 4. Comparison of parasitological methods for the diagnosis of strongyloidiasis in HIV-positive and HIVnegative patients in Itajaí, SC, Brazil, 2001-2002 ( $\mathrm{n}=33$ )

\begin{tabular}{lccc}
\hline Diagnostic methods & $\begin{array}{c}\text { Positive tests/S. stercoralis } \\
\text { positive patients }\end{array}$ & Observed proportion & P values \\
\hline Agar plate & 23 & 0.697 & $0.012^{*}$ \\
Lutz & 14 & 0.424 & \\
Agar plate & 23 & 0.697 & $0.0398^{*}$ \\
Formalin-ethyl acetate & 16 & 0.484 & \\
Agar plate & 23 & 0.697 & $0.0398^{*}$ \\
Baermann & 16 & 0.484 & $0.001^{* *}$ \\
Agar plate & 23 & 0.697 & \\
Harada-Mori & 8 & 0.247 & \\
\hline
\end{tabular}

Observed proportion test; significant statistical value: $* \mathrm{P}<0.05 ; * * \mathrm{P}<0.01$. 
found parasite in HIV-positive (10\%) and HIV-negative (7.8\%) patients (Table 1). The high frequency of this helminth in both groups, which surpassed even the infection by $A$. lumbricoides, could be due to the fact that three different techniques, which are specific for the detection of nematode larvae, were used in this study: the Baermann method, Harada-Mori culture and the agar plate technique. When Lutz's method was used as the only detection method, A. lumbricoides was the most frequently found parasite, which is what has been found in most parasitological surveys [16,17].

The HIV-positive patients were more susceptible to infection by $S$. stercoralis, compared to the HIVnegative patients (odds ratio $=5.687$ ). This observation is similar to what was found in previous studies, where the parasite seems to be constantly associated with infection by HIV [18].

We examined specific methods, which could provide a more efficient diagnosis, in the search for $S$. stercoralis larvae. The frequency of this parasite might be underestimated, since characteristic symptoms are not always noticeable [19]. Feltz et al. [20] considers that the larvae of this helminth are often difficult to find in stools, as they are excreted in minimal amounts and intermittently by the host, therefore requiring sensitive detection techniques.

Definitive diagnosis of strongyloidiasis is usually made on the basis of detection of larvae in stools. Microscopical examination may be used on fresh specimens, or on shortterm in vitro cultures of larvae. Concentrating the feces with formalin-ethyl acetate increases the positivity, but dead individual larvae are more difficult to recognize at low magnification. The Harada-Mori culture method makes use of the ability of $S$. stercoralis to enter a freeliving cycle of development, but it is rarely adopted as a standard procedure in clinical parasitology laboratories [1]. The Baermann technique, which takes advantage of the hydrotropism of nematode larvae, is believed to be a more sensitive method to perform the diagnosis of strongyloidiasis [19]. However, this method uses a funnel or a flask to deposit the fecal material from each sample, which is cumbersome. Thus, this may explain why the prevalence of stongyloidiasis is often underestimated [21].
Diagnosis of $S$. stercoralis in agar plates has recently been employed and compared to direct smear and Harada-Mori filter paper methods, giving superior results [10]. Other researchers have made comparisons between the agar plate method, and the formalin ethyl acetate, direct smear and Harada-Mori methods. They concluded that the agar plate was the most efficient method on the diagnosis of this parasite [9,3,22,12]. Feltz et al. [20] stated that Baermann's and agar plate techniques also depend on the number of samples analyzed. They also concluded that concentration in formalin-ether is not adequate for searching for larvae, due to its low sensitivity. Other researchers found that the agar plate method is more efficient when compared to other techniques traditionally adopted in clinical laboratories [13]. According to Hernadez-Chavarria [19], Baermann's and agar plate's methods give similar results in the search for S. stercoralis, and both were more efficient than other methods used to find this helminth.

We compared the agar plate method with four other methods: formalin ethyl acetate, Harada-Mori culture, Baermann and Lutz. The agar plate method was found to be more sensitive than Baermann's standard method, which had not been previously studied. Table 4 shows the results from these analyses. Among 424 feces samples, S. stercoralis was detected in 33 (7.8\%).

The helminth was found with the agar plate method in 23 samples (69.7\%). The Baermann and formalin ethyl acetate methods detected this parasite in 16 samples (48.5\%), Lutz's method detected the parasite in 14 samples (42.4\%) and the Harada-Mori culture method detected the parasite in 8 samples $(24.0 \%)$. It became clear that the agar plate method is superior for the detection of S. stercoralis larvae; this difference was especially pronounced when the agar plate method was compared with the Harada-Mori filter paper method $(\mathrm{P}<0.001)$.

The agar plate method was, on average, $45 \%$ more efficient than the other methods, such as formalin ethyl acetate and Hoffman in the search for larvae. However, the agar plate method appears to be efficient only for S. stercoralis, since its detection rate of hookworms is lower than with the filter paper method. Koga et al. [23] came to a similar conclusion, and stated that the 
incubation period used for S. stercoralis does not appear to be sufficient for hookworms.

On the other hand, the procedure that uses formalin to wash the agar plate and sedimentation to collect the worms had some advantages, since the tracks left by the larvae on the agar surface could not always be observed. According to Sato et al. and Dreyer et al. [22,24], other factors are relevant and may contribute to a more efficient search for larvae, such as collecting feces samples on three consecutive days, which may result in increased positivity. The increase in the detection rate of $S$. stercoralis larvae with the agar plate method could also be due to the possibility of detection of free-living species of the larvae, which can be found in the indirect cycle [25], and also with the higher number of larvae found using this method, when compared to Baermann's method.

The choice of parasitological examination for routine diagnosis takes into account sensitivity and costs. Very little technical expertise is needed and there are minimal costs with the agar plate method, yet it is much more sensitive than Baermann's standard method. The agar plate method is usually not adopted routinely in the parasitological examination of feces, however we recommend this method for suspect cases of strongyloidiasis, especially in immunocompromised individuals, and also in those patients who need to be treated with immunosuppressive drugs.

\section{References}

1. Siddiqui A., Berk S. Diagnosis of Strongyloides stercoralis infection. Clin Infec Dis 2001;33(1):1040-7.

2. Figueiredo F., Pelosi A., Bloise P. Estrongiloidíase disseminada: relato de um caso e revisão da literatura. J Bras Patol 2000;36(1):12-7.

3. Salazar S.A., Gutierrez C., Berk S. Value of the agar plate method for the diagnosis of intestinal Strongyloides stercoralis. Diagn Microbiol Infect Dis 1995;23:141-5.

4. Trajman A., Macdonald T., Elia C. Intestinal immune cells in Strongyloides stercoralis infection. J Clin Pathol 1997; 50(12):991-5.

5. Fallas S., Hernández F., Mora N., et al. A. Strongyloides stercoralis: una discusión sobre su diagnóstico coproparasitológico y su prevalencia en pacientes positivos por el virus de la inmunodeficiência humana (VIH). Acta Med Costar 2000;42(1):31-4.
6. Feitosa G., Bandeira A., Sampaio D., et al. High prevalence of giardiasis and strongyloidiasis among HIV-Infected patients in Bahia, Brazil. Braz J Infec Dis 2001;5(6):339-44.

7. Lindo J., Dubon J., Ager A., et al. Intestinal parasitic infections in human immunodeficiency virus (HIVpositive) and HIV-negative individuals in San Pedro Sula, Honduras. Am J Trop Med Hyg 1998;58(4):431-5.

8. Punpoowong B., Viriyavejakul P., Riganti M., et al. Opportunistic protozoa in stool samples from HIVinfected patients. J Trop Med Public Health 1998;29(1):31-4.

9. Koga K., Kasuya S., Khamboonruang C., et al. An evaluation of the agar plate method for the detection of Strongyloides stercoralis in northern Thailand. J Trop Med Hyg 1990;93:183-8.

10. Arakaki T., Iwanaga M., Kinjo F., et al. Efficacy of agarplate culture in detection of Strongyloides stercoralis infection. J Parasitol 1990;76(3):425-8.

11. Waywa D., Kongkriengdaj S., Chaidatch S., et al. Protozoan enteric infection in AIDS related diarrhea in Thailand. South Asian J Trop Med Public Health 2001;32(suppl 2):151-5.

12. Kobayashi J., Hasegawa H., Soares E., et al. Studies on prevalence of Strongyloides stercoralis infection in Holambra and Maceió, Brazil, by the agar plate fecal culture method. Rev Inst Med Trop 1996;38(4):279-84.

13. Uparanukraw P., Phongsri S., Morakote N. Fluctuations of larval excretion in Strongyloides stercoralis infection. Am J Trop Med Hyg 1999;60(6):967-73.

14. De Carli G. Parasitologia clínica. São Paulo:Atheneu, 2001:809.

15. Boletim epidemiológico aids. Ano XV, n. 1, 48/2001 à 13\%a 2002. Semanas epidemiológicas out. de 2001 a março 2002. Disponível em <http://www.aids.gov.br $>$ Acesso em: 06 mar. 2003.

16. Cantos G., Aléssio G., Duccioni L., et al. Estudo comparativo da prevalência de enteroparasitas em pacientes atendidos em dois Laboratórios de Florianópolis, SC. NewsLab 2002;54:126-30.

17. Benetti A., Bertuzzo D. Estudo da incidência de principais parasitas humanos na comunidade ribeirinha do bairro Canhandúba no Município de Itajaí, durante o primeiro semestre de 2002. Itajaí, 2002. Monografia. Graduação. Curso de Farmácia, Universidade do Vale do Itajaí.

18. Cimerman S.; Cimerman B.; Leni, D. Prevalence of intestinal parasitic infections in patients with acquire immunodeficiency syndrome in Brazil. Int J Infect Dis 1999;3(4):203-6.

19. Hernandez-Chavarría H.F. Strongyloides stercoralis: un parásito subestimado. Parasitol al día 2001;25(1-2):40-9.

20. Feltz M., Slee P., Hees P., Tersmette M. Strongyloides stercoralis infection: how to diagnose best? J Méd 1999;55(3):128-31. 
21. Hernández-Chavarria F., Avendaño L. A simple modification of the Baermann method for diagnosis of strongyloidiasis. Mem Inst Oswaldo Cruz 2001;96(6):805-7.

22. Sato Y., Kobayashi J., Toma H., et al. Efficacy of stool examination for detection of Strongyloides stercoralis infection. Am J Trop Med Hyg 1995;53(3):248-50.

23. Koga K., Kasuya S., Khamboonruang C., et al. A modified agar plate method for detection of Strongyloides stercoralis. Am J Trop Med Hyg 1991;45(4):518-21.

24. Dreyer G., Fernandes-Silva E., Alves S., et al. Patterns of detection of Strongyloides stercoralis in stool specimens: implications for diagnosis and clinical trials. J Clin Microb 1996;34(10):2569-71.

25. Atkins N., Lindo J., Lee M., et al. Tumoral responses in human Strongyloidiasis: correlation with infection chronicity. Trans Royal Soc Trop Med Hyg; 1997;91:609-61. 